\title{
Nos limiares do jogo de espelhamento literário-discursivo
}

The thresholds of the literary-discursive mirroring game

\author{
Atilio Catosso Salles ${ }^{1}$ \\ Universidade do Vale do Sapucaí \\ Eliana de Almeida \\ Universidade do Estado de Mato Grosso
}

\section{Resumo}

Inscrevemos este trabalho de leitura pelo viés teórico da Análise de Discurso (PÊCHEUX, 1988; ORLANDI, 1999; PAYER, 2006, MARIANI, 2008 e AUTHIER-REVUZ, 1998), perguntando pelos modos a partir dos quais a escrita jornalística materializa e produz sentidos para o sujeito e para própria língua. O corpus "bruto" é constituído por um arquivo de jornais do século XIX que circularam em Cuiabá-MT. A temática do corpus, pela delimitação dos recortes, é a construção dos percursos de sentidos da posição sujeito-articulista, em face de algumas formulações poético-literárias. No que segue, apresentaremos inicialmente os pressupostos teóricos materialistas que dão alicerce para a reflexão da memória discursiva e a sua relação com a língua no século XIX. Em seguida, será proposto um estudo de uma tríade conceitual: língua, poesia e memória, com o objetivo de escavar, desvendar os vastos indícios do funcionamento da memória na língua, face aos deslocamentos reflexivos dos sentidos, dos sujeitos no mundo, pelas suas possibilidades de dobras que produzem ficção.

\section{Palavras-chave}

língua; memória; poesia; alteridade; jornal. 


\section{Abstract}

We have written this work based on the theoretical framework of Discourse Analysis (PÊCHEAUX, 1988; ORLANDI, 1999; PAYER, 2006, MARIANI, 2008 and AUTHIER-REVUZ, 1998), aiming at investigating the modes through which journalistic writing embodies and produces meanings for the subject and for language itself. The corpus analyzed consists of a file of newspapers from the nineteenth century that were put around in Cuiabá-MT. The corpus theme is the construction of the meaning paths of the subject in the reporterposition, concerning some poetic-literary formulations. As a next step, we present the materialistic theoretical assumptions that enable the reflection about discursive memory and its relationship with the language of the nineteenth century. Then, a study on a conceptual triad is proposed: language, poetry and memory, aiming at excavating and unraveling the vast evidence of memory in language, concerning the reflective displacement of meanings and of subjects in the world, through the main fold ways by which fiction is produced.

\section{Keywords}

language; memory; poetry; alterity; newspaper. 


\section{Introdução}

s reflexões que ora apresentamos integram um estudo amplo, apenas
iniciado, cujo objetivo primeiro, a partir da perspectiva da Análise de Discurso, é a investigação das práticas discursivas no espaço de dizeres do jornal ( $A$ Opinião, 1878; O Povo, 1879).

Diante das reflexões teóricas desenvolvidas no interior do grupo Cartografias da Linguagem, que objetiva o estudo da história das ideias linguísticas no Brasil, inscrevemos este trabalho, buscando dar visibilidade aos processos de construção da nacionalidade do sujeito brasileiro numa relação com a língua.

É pela história da constituição de uma língua que, segundo Orlandi (2002), podemos tomar como materialidade de análise a história de um país e de suas instituições. Assim, visamos a dar visibilidade às produções e aos espaços discursivos produzidos pela imprensa mato-grossense no processo de constituição dessa língua nacional no espaço mato-grossense do século XIX.

Tomamos esse funcionamento discursivo da escrita jornalística do século XIX, em jornais ( $A$ Opinião, 1878; O Povo, 1879) que circularam no estado de Mato Grosso, numa relação com a produção literária de José de Alencar, mais especificamente no ano de sua morte (1877), como material de análise. Filiamo-nos à teoria da Análise de Discurso, investigando os modos a partir dos quais a escrita jornalística materializa e produz sentidos para o sujeito e para a própria língua. Observando a linguagem jornalística enquanto espaço de espelhamento da relação língua/sujeito/mundo, problematizamos o estudo dessa relação a partir de Orlandi (2001; 1990), Pêcheux (1998), Payer (2006), Mariani (2008) e Authier-Revuz (1998), questionando como se constitui o espaço de repetição nesse material que foi recortado para leitura, pois, em um primeiro contato, observamos os dizeres silenciados por outros dizeres da memória sócio- 
histórica que constitui o sujeito do XIX.

Os textos jornalísticos, que tomamos como materialidade linguística ao dizer sobre José de Alencar, acabam por produzir inconscientemente um efeito de alteridade, ou seja, o Outro da língua se torna constitutivo do sujeito articulista. Desse modo, propusemos questionar, em nosso corte, as noções teóricas de sujeito e língua para observar como se constitui um sujeito dividido-desdobrado no espaço do mesmo e do outro e também o jogo de formações discursivas entre si, do discurso e o outrem, que é produzido na materialidade da língua.

Assim, nesse batimento-pulsão os sentidos serão tomados, como gestos de leitura que definem a posição mato-grossense em relação à configuração do sujeito nacional e da própria língua em movimento, no jogo discursivo da imprensa em Cuiabá.

\section{Outros no mesmo: por um funcionamento literário-discursivo no Jornal}

"[...] nenhuma palavra é virgem, mas, ao contrário, carregada, "habitada" pelos discursos em que tenha vivido sua vida de palavra [...].”. (AUTHIERREVUZ, 1999, p. 9-10)

A língua constitui o sujeito dividido-desdobrado no espaço do mesmo e do Outro e também o incrível jogo de imagens mútuas entre si e outrem (enunciador), que é produzido na materialidade da língua. Assim, os sentidos serão tomados como gestos de leitura que definem a posição mato-grossense em relação à configuração do sujeito nacional e da própria língua em movimento, no jogo discursivo da imprensa em Cuiabá.

Para melhor traçar o percurso analítico, empreenderemos um estudo dessa relação a partir das noções das não-coincidências, desenvolvidas por Authier-Revuz (1998), para problematizar a forma como se constitui o espaço de repetição, em que um dizer silencia outros dizeres da memória sócio-histórica, 
que constitui e determina o sujeito. Dentre os quatro campos de já mencionadas não-coincidências ou heterogeneidade, segundo Authier-Revuz (1998), que o dizer produz/desdobra, recortamos para essa leitura apenas duas: a não-coincidência do discurso consigo mesmo e a não coincidência das palavras com elas mesmas. Para a autora, o modo de representação das não-coincidências não leva em conta a intencionalidade, já que elas se evidenciam na língua ao mesmo tempo como máscaras delas mesmas.

A não-coincidência constitutiva da língua em relação a si mesma se estabelece como um já-lá da memória discursiva própria da língua. Vejamos uma formulação publicada no jornal O Povo (1879 - ano I), em que Tavares, articulista desse jornal, refere-se ao poeta Gonçalves Dias:

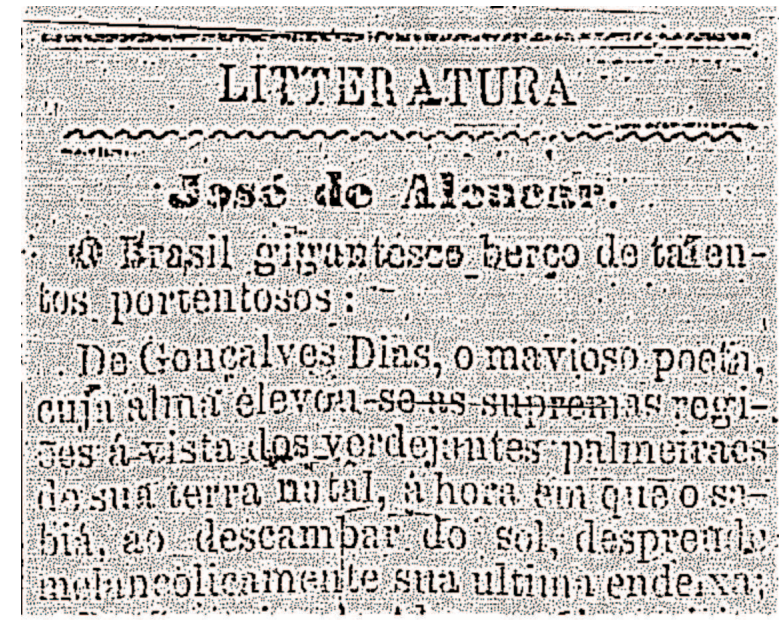

(TAVARES J. ano I, 1879) $)^{2}$

Blanchot (1987) discute, no campo da teoria literária, que no lugar onde está o escritor só fala o ser. Assim, a posição-escritor torna-se constitutiva de um discurso em que, a priori, ninguém fala, pois quem fala nesse discurso é uma decorrência do fato de que, de uma maneira ou de outra, já não é ele mesmo (o articulista), já não é ninguém. É, pois, a partir dessa compreensão, que propomos à leitura dessa materialidade simbólica, a língua, numa relação com a memória do discurso jornalístico e literário. 
Consideramos a alteridade, a partir de Leite (2007, p.11), enquanto um lugar de representação do inconsciente, e um inconsciente "[...] estruturado como linguagem, que se desdobra nos efeitos de linguagem".

O ritual discursivo de escritura não é consciente para o articulista, uma vez que nesse gesto ele é já capturado pelos efeitos do inconsciente. O sujeito encontra-se submetido à linguagem e, principalmente, habitado nela e por ela, constituindo-se enquanto discurso. A partir disto, compreendemos que Tavares - o articulista - ao escrever sobre o poeta Gonçalves Dias, o faz a partir de um discurso já-dado, o discurso literário, possível na língua nacional brasileira em sua cadeia significante. Trata-se de um gesto de escritura clivado pelo inconsciente e habitado por uma natureza e alma poética.

O gesto discursivo de escritura, que recortamos de Tavares, significa-se nessa alteridade da não-coincidência do discurso consigo mesmo na medida em que se inscreve no já-dito de uma formulação literária. Essa reflexividade da língua condensa-se nas formulações de Tavares como se fosse o próprio Gonçalves Dias formulando nessa língua do século dezenove, em Mato Grosso.

Gadet \& Pêcheux (2004) apontam para o fato de que a materialidade simbólica da língua se dá enquanto espaço discursivo diverso para formulações poéticas, como em "[...] o poeta seria apenas aquele que consegue levar essa propriedade da linguagem a seus últimos limites".

Na homenagem a Alencar, publicada no jornal A Opinião (1878 - ano I), temos:

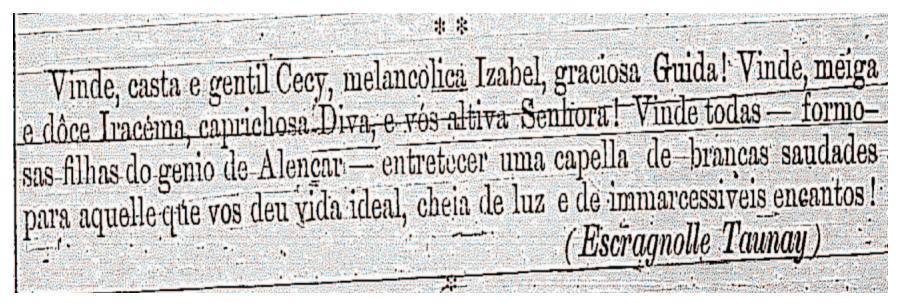

(Escragnolle Taunay, 1878 - ano I) ${ }^{3}$

Nessas formulações, Taunay inscreve-se, enquanto articulista, na posição literária de Alencar em relação à língua, "não de si" que se impõe como 
um dizer "disto do qual se fala". Trata-se de formulações poéticas de um mesmo lugar, mesma época, porém, em outras condições de produção, construídas por outro interlocutor. O gesto discursivo de escritura de Taunay, embora seja no jornal, inscreve-se no saber poético já-dado em Alencar na/sobre a língua, constituindo sentidos no mundo pelo saber suposto sobre essa mesma língua.

Do mesmo modo que Tavares, o gesto de escritura de Taunay repete/reformula sentidos na/pela língua nacional brasileira, nessas partículas de elaboração da língua "não de si", elevadas aos seus limites simbólicos, pela escolha do léxico, pelo ritual dessa sintaxe da escrita, pelo excesso das predicações, etc., em relação à proposição de que, segundo Orlandi, os sentidos não estabelecem espaços fixos ou particulares em uma dada formulação possível da língua:

O dizer não é propriedade particular. As palavras não são só nossas. Elas significam pela história e pela língua. O que é dito em outro lugar também significa em "nossas" palavras. O Sujeito diz, pensa que sabe o que diz, mas não tem acesso ou controle sobre o modo pelo qual os sentidos se constituem nele. (ORLANDI, 2005, p.32)

Daí pensarmos o lugar de constituição da memória dessa língua nacional no século XIX, em que Tavares e Taunay, num gesto duplo, significamse no mesmo modo em que a língua está inscrita pelos processos de identificação na relação sujeito/língua/nação.

Nessa direção, Mariani (2004) discute a importância primeira da compreensão histórica dos processos de produção de sentidos no modo como o sujeito irá se significar na/pela língua. A autora aponta que as produções de sentidos estão entrelaçadas a diferentes lugares ocupados pelo sujeito em dada formação social. Assim, há a possibilidade de sujeitos, a partir de uma mesma língua, significarem-se de maneira diferente.

Na mesma perspectiva, Payer (2006) afirma que o ritual discursivo, seja em qualquer conjuntura dada, estabelece uma relação intrínseca com a memória, a partir da circularidade na sociedade e na história. Assim, a forma-sujeito arti- 
culista/poeta (ocupando as mesmas posições sujeito) do século XIX está afetada por uma memória de um discurso literário no modo como circula e significa a relação língua/sujeito/mundo. Dessa forma, a língua supõe memória, ao ser passível de repetição para significar-se, e os sentidos, que a constituem, circunscrevem formas-sujeito escritor que se estruturam diferentemente, de acordo com a posição ideológica que assumem.

A identidade de uma nação, no espaço do século XIX, aspira à construção de uma natureza que nos remete a apreciação de um contexto grandioso e harmônico. Como recurso estilístico, o articulista/poeta brinca com jogos de personificação, remetendo-nos a elevação desses elementos naturais tidos como nacionais e/ou específicos de uma nação: "[...] gigantesco berço/eleva-se as supremas regiões à vista das verdejantes palmeiras de sua terra natal, à hora em que o sabiá descambar do sol desprende melancolicamente sua última endeixa [...]" (TAVARES J. ano I, 1879).

Esse funcionamento discursivo, representado na citação de Tavares próprio da língua, conforme Gadet \& Pêcheux (2004) - é significado, de certo modo, a partir de um saber suposto da escrita poética, circunscrevendo a criação de um mundo e admitindo a ficção da própria língua, do mundo. Nesse sentido, Almeida (2010, p.7) afirma que "[...] o signo constitui-se metalíngua à medida que aponta para o significado de algo - o mundo fictício, ao mesmo tempo em que o significa no modo como se dá - como a língua o significa. Ou seja, o signo é reiterativo de sentidos, porque significa algo e o significa de certo modo".

Dessa maneira, é na reiteração dos sentidos, na biâncid de marcar um sujeito nacional, cuja possibilidade de deslizamentos se faz presente, que a poesia está, no próprio da língua enquanto lugar de todo processo de significação. Assim, as versões de um nacionalismo e identidade linguística são, de acordo com Mariani (2008, p.26), "[...] projeções que, tomando a língua como objeto simbólico da nação, fazem consistir a língua nacional de acordo com predicações que a qualificam 'sendo isso ou aquilo' ou que a caracterizam como tendo isso ou aquilo".

Esse lugar não-de-si de dizer a poesia na língua é marcado como constitutivo do discurso do Outro, sendo possível especificar fronteiras entre si e o 
Outro em suas diferentes instâncias de condições de produção: diferentes interlocutores, épocas, materialidades de divulgação, etc. O discurso da/sobre a língua mantém-se o mesmo e ressignifica-se no movimento da história, produzindo em si mesmo, por diferença, sua própria imagem, conforme Authier-Revuz (1998).

A relação língua/sujeito/história, que a princípio estabelece uma unidade imaginária política/linguística, no cenário do XIX, desliza-se por palavras porosas de um discurso constitutivo, pelas quais restitui, no coração dos sentidos sobre a língua, uma carga nutriente e destituinte (AUTHIER-REVUZ, 1998).

O excesso das predicações, nesse material que recortamos, produz o efeito de condensação de sentidos possíveis pela formulação da poesia na língua:

[...] Brasil gigantesco, berço de talentosos portentosos, o mavioso poeta, supremas regiões, verdejantes palmeiras, terra natal, última endeixa [...] (TAVARES J. ano I, 1879). Casta e gentil Cecy, melancólica Izabel, graciosa Guida, meiga e doce Iracema, caprichosa Diva, altiva Senhora, formosas filhas, gênio de Alencar, brancas saudades, vida ideal, cheia de luz, imarcescíveis encantos (Escragnolle Taunay, 1878 - ano I).

As predicações, ao serem atribuídas a essa língua, produzem um movimento de completude, na tentativa de se representar e se fixar uma identidade. Todavia, a incompletude é umas das condições da linguagem, visto que nem tudo pode ser dito, sempre há algo por ainda dizer, algo que escapa ao simbólico e permanece na esfera do indizível. A isso denominamos real da língua.

Nessa direção, Mariani formula:

Há real: há pontos de impossível determinando o que não pode não ser dito de outra maneira. É porque há real, algo que escapa ao simbólico, que nos deparamos com a falha na cadeia significante e com seus efeitos, ou seja, os deslizamentos de sentidos, os equívocos, os atos falhos. . (MARIANI, 2008, p. 26) 
Dessa maneira, os dizeres não são óbvios, já que é no real das não-coincidências que há o afetamento do Outro, lugar em que se produzem sentidos. É por isso que as palavras que enunciamos não falam por si, e, desse modo, a opacidade da relação língua/sujeito/história nos conduz a pensar os lapsos, os atos falhos e os equívocos como sendo constitutivos da linguagem, marcados pela incessante voz do Outro, fazendo com que nossas palavras não sejam intactas, mas sim habitadas por outras vozes.

Para Orlandi (2007, p.31), o movimento da memória, enquanto um "[...] saber discursivo que torna possível todo dizer e que retorna sob a forma do pré-construído, o já dito que está na base do dizível sustentando cada tomada da palavra", circunscreve sentidos no modo mesmo como esses sentidos estão já constituídos na língua. Portanto, a dobra de mundos, sujeitos e sentidos produzindo ficção é um funcionamento próprio da língua, pois o sujeito não tem sempre um lócus de filiação; ele é determinado sócio-historicamente e afetado pelo inconsciente. Não há dizeres preenchidos e pré-determinados. Afinal, "[...] nenhuma língua pode ser pensada completamente, se aí não se integra a possibilidade da poesia" (PÊCHEUX, 1990, p. 51), da ficção e da representação pela dobra.

O poético, desse modo, é pensando como propriedade da língua, não sendo restrito a um espaço de efeitos, a ser usado em momentos ou ocasiões específicas; ao contrário, pode ser concebido "[...] como uma propriedade da ordem da língua [...] que incide no corpo da língua, em sua materialidade significante" (GADET \& PÊCHEUX 2004, apud, MARIANI, s/d, p. 1).

O efeito de deslizamento no fio discursivo coloca em jogo o modo como a língua imita o real, à deriva de um funcionamento fictício, poético. Acerca disso, Mariani considera que

"[...] do ponto de vista discursivo, o poético não está fora da linguagem, não é algo restrito a um conjunto de efeitos especiais a ser usado em determinadas ocasiões. Ao contrário, pode-se conceber como uma propriedade da ordem da língua essa capacidade de deslizamento do poético". (MARIANI, 2007, p. 213-228) 
Para Gadet \& Pêcheux a poesia flui, no fio discursivo da língua, como efeitos especiais estruturantes de deslizamentos próprios a seus processos de significação:

Diante das teorias que isolam o poético do conjunto da linguagem, como lugar de efeitos especiais, o trabalho de Saussure [o dos anagramas] (tal como ele é, por exemplo, comentado por Starobinski) faz do poético um deslizamento inerente a toda linguagem: o que Saussure estabeleceu não é uma propriedade do verso saturnino, nem mesmo da poesia, mas uma propriedade da própria língua. O poeta seria apenas aquele que consegue levar essa propriedade da linguagem a seus últimos limites; ele é, segundo a palavra de Baudrillard, suprimindo a sua acidez, um "acelerador de partículas da linguagem”. (GADET \& PÊCHEUX, 2004, p.58)

A língua, pensada pela teoria materialista da linguagem, tem sua ordem própria, apesar de ser "sujeita a falha", a deslizamentos, a rupturas, a buracos próprios em sua rede significante por onde incide a metáfora, o efeito poético. Os sentidos assim não podem ser domesticados. Afinal, não há univocidade e transparência de linguagem, de palavras, e, por conseguinte, de sentidos. O que há é deriva de sujeitos/sentidos/mundos no espaço mesmo de uma língua inatingivel, cuja possibilidade de produção do poético se faz. Desse modo, os processos de subjetivação se dão em espaços de não filiação e de incompletude, assim "[...] nada da poesia é estranho à língua. [...] nenhuma língua pode ser pensada completamente se aí não se integra a possibilidade de sua poesia" (PÊCHEUX, 1990, p. 51). O poético, portanto, não está fora da linguagem e só podemos pensar na língua a partir do momento em que se abre a possibilidade da poesia, da criação, movimentos de transgressão e de instauração de um devir. Authier-Revuz (1998), como dito, aponta o duplo da heterogeneidade dos sentidos da língua, sob a denominação de quatro não-coincidências do dizer, duas das quais já foram expostas em nosso percurso de estudo: não-co- 
incidência interlocutiva entre o enunciador e o destinatário e a não-coincidência do discurso com ele mesmo.

No estudo da autora, incluem-se ainda as não-coincidências que ocorrem entre as palavras e as coisas e as das palavras com elas mesmas. Assim, para compor nosso trajeto de leitura, recortamos ainda a quarta das não-coincidências - a das palavras com elas mesmas 5 , na qual o locutor procura um sentido para determinada palavra, a partir da exclusão de outros sentidos possíveis. Essa representação do dizer consagra o sistema linguístico de unidades distintas, e testemunha o encontro dos enunciadores com o equívoco, segundo AuthierRevuz (1998, p. 25) em quatro esferas: "(1) respostas de fixação de um sentido; (2) figuras do dizer alterado pelo encontro com o não-um; (3) o sentido estendido no não-um; (4) o dizer reafirmado pelo não-um".

Nessa não-coincidência, a autora parte das considerações de Lacan sobre o equívoco da homonímia, que está estreitamente relacionado ao dizer das glosas, das quais decorrem os efeitos de polissemia, homonímia e/ou trocadilhos.

Vejamos o funcionamento das glosas, na homenagem feita a Alencar, no jornal A Opinião (1878, ano I):

Entre as joias preciosas do rico thesouro com que José de Alencar, -ennobrecendo a patria, immortalisou seu nome, se admiro sempre a grandeza de seu talento, a seiva inesgotavel de suas inspirasóes, e o vasto cabedal de conhecimentos que tanto realgavam suas.obras, a que mais me encantou foi o primoroso mimo de sua imaginaça de poeta, intitulado Sonhos de Ouro.

Nāo tern' porventura o merito intrinseco de muitas de suas outras producçôes, nāo revelara' como nestas o estudo e a meditaçă, mas nenliuma deleita mais o espinito, porgue-nenhtma seguranrente a excedle na belloza da forma, na naturalidade dó entrecho, e, muis que tudo, na pureza e elevação do sentimento. Nos Sonhos de Ouro é protogonistá ${ }^{\circ}$ coraçá en toda gala e esplendor de seusprimeiros impulsus e percorrendo enibevecido a éscala esperançosa das enrogóes electricas do amor. Os Sonhos de Ouro, ainda-uma vez o digo, săo o transump. to perfeito da alma de Jose de Alenear.

\section{( J.P. lle Azevedo Pecanha).}

(PEÇANHA, 1878 - ano I) ${ }^{6}$

Peçanha, no gesto de homenagear Alencar, produz um discurso que matiza modalidades irrealizáveis de dizer, ou seja, produz, pelas glosas de sentido, um jogo que evoca sempre um sentido a mais, irrealizável sobre a palavra na cadeia significante da língua. 
Além ou aquém do estudo desses discursos diversos, através dos quais se procura um sentido para as palavras, pela própria exclusão de outros sentidos possíveis, o nível excessivo de deslizamentos, reduzidos a "[...] fenômenos lúdicos, ou acidentais, do lado da recepção, a dimensão do equívoco do dizer" (AUTHIER-REVUZ, 1998, p. 25), produz um efeito especular duplo na linearidade do fio discursivo da língua. Vejamos: joias preciosas, seiva inesgotável, vasto cabedal, mimo de sua imaginação, deleita o espírito, pureza e elevação dos sentimentos, o coração em toda a gala, esplendor de seus primeiros impulsos, embevecido, esperançosa das emoções elétricas do amor, transumpto perfeito da alma; todas essas são expressões que manifestam, na superfície do dizer, as não-coincidências das palavras consigo mesmas, fazendo referência ao "jogo da língua", citado por Lacan como lalangue, aquela em que se ancora a poesia.

Assim, esse espaço não-de-si do século XIX, ao dizer a poesia na/da língua, a partir de jogos da linguagem, mostra, nas produções jornalísticoliterárias, um redemoinho de palavras, uma possível armadilha, que escapa ao sujeito, conforme observamos na proposição que segue de Carlos França, publicada no jornal $A$ opinião, ano I:

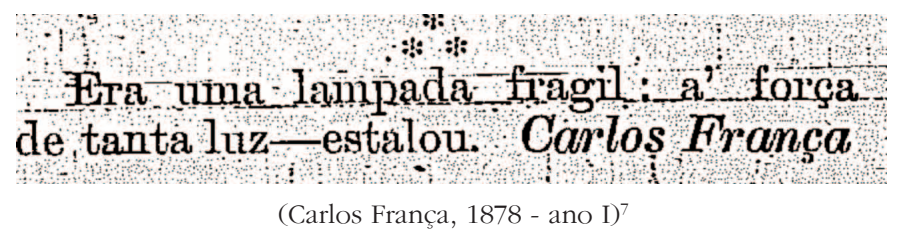

Essa propriedade da reflexividade, nesse recorte, se manifesta pela retomada da linguagem no interior dela mesma, instaura a incompreensão, os mal-entendidos, a ambiguidade [...], devido à necessidade de se fixar o $\mathrm{um}$, tido como transparente da linguagem, negando o estranho a esse não um, o Outro. (AUTHIER-REVUZ, 1999).

Segundo Pêcheux (1983, p.53), toda descrição "[...] está exposta ao equívoco da língua: todo enunciado é intrinsecamente suscetível de tornar-se outro, diferente de si mesmo, se deslocar discursivamente de um sentido para derivar para um outro". O mesmo se verifica nesse espaço onde são tecidas as homenagens a Alencar, ou seja, no intrincamento das falas dos discursos, sob a 
forma de um pré-construído ou já-dito, próprio do fio discursivo, que possibilita inaugurar discursos outros, pela tomada de posição do sujeito, que, ao formular, remonta sempre a um já-lá das formulações possíveis da língua.

Vejamos como Authier-Revuz problematiza a homogeneidade ou a ilusão de unicidade da língua/sentido/sujeito, face ao caráter da heterogeneidade:

A dupla designação de um fragmento outro e da alteridade a que remete constitui, por diferença, uma dupla afirmação do um. Ao nível da cadeia do discurso, localizar um ponto de heterogeneidade é circunscrever este ponto, ou seja, opô-lo por diferença do resto da cadeia, à homogeneidade ou à unicidade da língua, do discurso, do sentido etc.; corpo estranho delimitado, o fragmento marcado recebe nitidamente através das glosas de correção, reserva, hesitação, um caráter de particularidade acidental, de defeito local. Ao mesmo tempo, remete a um alhures, a um exterior explicitamente especificado ou dado a especificar, determina automaticamente pela diferença Um interior, aquele do discurso; ou seja, a designação de um exterior específico é, através de cada marca de distância, uma operação de constituição de identidade para o discurso. (AUTHIER-REVUZ, 1990, p.31)

A partir dessa consideração, a noção do duplo da heterogeneidade, exposto à falha própria da língua que a autora denomina de não-coincidências do dizer, inscreve-se especularmente no eixo da linearidade, possibilitando especificar o Outro do discurso que atravessa/constitui o um de modo mais marcado.

Ao lado das não-coincidências do dizer, no fio discursivo, encontramos laços metaenunciativos de dizeres que retomam reflexivamente um determinado ponto de seu desenvolvimento, desdobrando sentidos que "[...] correspondem a um dos campos nos quais se realiza a configuração enunciativa complexa da modalização autonímica". (AUTHIER-REVUZ, 2010, p.255) A autora, nesse estudo, privilegia as formas marcadas diretamente, visíveis no fio discursivo, constituindo uma escala que vai desde as formas mais explícitas até as menos claras: 
1) formas explicitamente metaenunciativas "completas", comportando um eu digo X; 2) formas explicitamente metaenunciativas que implicam em eu digo $\mathrm{X}$, subordinadas e sintagmas circunstâncias, aposições; 3) formas explicitamente metalingüísticas, como um autônimo $\mathrm{X}$ ou $\mathrm{Y}$; 4) formas sem elementos autônimo, ou sem elemento metalingüístico unívoco; 5) sinais tipográficos (aspas, itálico) e de entonação [...]; 6) formas puramente interpretativas [...] (AUTHIER-REVUZ, 1998, p.19).

O termo marcado faz referência a um discurso outro, o qual se dobra sobre o mesmo. Embora, não seja possível tomar essa marca como lugar de visibilidade, pois existe um processo de negociação em curso, as modalizações autonímicas podem perpassar desde formas marcadamente explícitas, às menos explícitas, até a um nível de não deixar nenhuma marca ou possibilidade descritível no fio do discurso.

A emergência da relação com o outro e o Outro, sob as formas da heterogeneidade explicitada/mostrada ocorre simultaneamente em dois domínios: primeiro, na relação do sujeito com seu outro exterior, construindo a representação do um e, segundo, na relação do sujeito com a língua, na qual "[...] constrói-se uma representação de sujeito que separa o que é seu e o que é de outro" (MORELLO, 1995, p.29).

Assim, recortamos dois enunciados, a partir da tessitura do jornal A Opinião:

i: Passaram-1he alii dolorosas pela mmaginação tódas estás verdades:

is. Tro-se todos os nossos homens de tálento.

A goin este, que escieven tantos e tão bellos livios!

Eira o autor do Guarairy.

Esse Guarany esta' hoje tradizido nir Funopa e den ensejo ao apprrecimento deim giande maestro nacional.

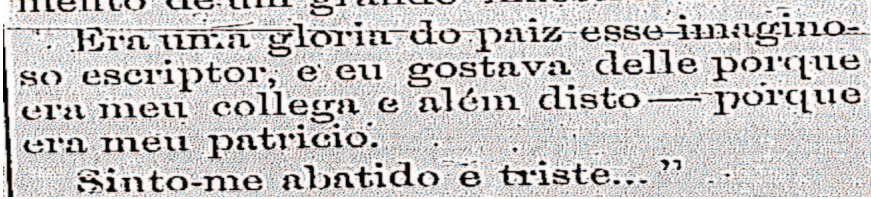

(G., 1878 - ano I) ${ }^{8}$ 
ii:

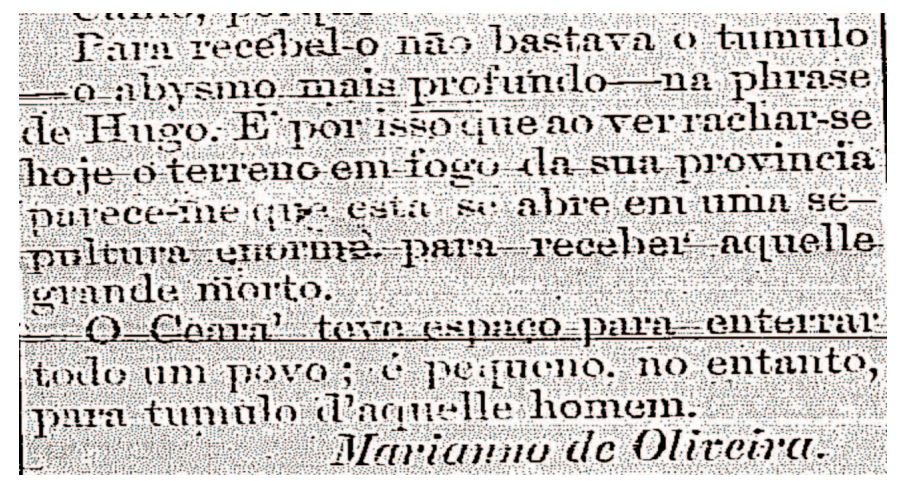

(Mariano Oliveira, 1878 - ano I) ${ }^{9}$

Apresentamos novamente que pensamos os sentidos enquanto espaço de "[...] multiplicidade, da largueza, mas também da truncação" (ORLANDI, 1990, p 43), espaço de emaranhamento dos dizeres possíveis de um já-lá da memória da língua.

Ao lermos os dois enunciados, podemos compreender que a alteridade que atravessa o fio discursivo designa o Outro no próprio ato de enunciação. A esse fenômeno denomina-se heterogeneidade mostrada marcada ou não marcada.

Authier-Revuz (1990) discute que a heterogeneidade mostrada e marcada se dá no momento em que o Outro explicitamente é notado, através das aspas, das glosas, do itálico, etc. Caso não haja nenhum indício explícito na materialidade da língua, temos a heterogeneidade mostrada, porém não marcada. Nessas situações a heterogeneidade apresenta-se apenas como efeito de um dito que se articula a um não dito, possível na reminiscência, na imitação, na alusão, etc.

No primeiro recorte, o comentário inicial dá visibilidade ao lugar discursivo no qual o enunciador do texto se põe a falar sobre Alencar: "Era uma gloria do paiz esse imaginoso escriptor, e eu gostava delle porque era meu collega e além disto - porque era meu patrício". É interessante também observar que o enunciado encontrado entre aspas foi especificado por uma glosa, utilizada pelo próprio articulista. Na glosa - "Vão-se todos os homens de talentos. 
Agora este, que escreveu tantos e tão bellos livros" - constitui-se o espaço do 'outro', o interlocutor, tornando-se visível, com isso, o efeito de que todo o restante do dizer é particular, original. Afinal, Alencar foi considerado, pelo próprio articulista, seu "patrício". Esse funcionamento discursivo mostra a distância existente entre os posicionamentos discursivos do articulista e do seu interlocutor, o que configura uma não-coincidência interlocutiva. As aspas materializam, assim, o contato do sujeito com o seu outro, pois delimitam o espaço que essa outra voz poderia ocupar, produzindo o efeito de unidade no ato discursivo.

No segundo enunciado, essa não-coincidência interlocutiva mostrada de modo não marcado se mostra quando Oliveira faz alusão às palavras de Victor Hugo (1802-1885): "Para recebê-lo não bastava o tumulo - o abysmo mais profundo - na frase de Hugo". O efeito de unidade, nesta segunda citação, é sinalizado pela distância que o articulista tenta impor, ao atribuir o sentido pelo discurso do outro, especificando assim, uma não-coincidência no fio discursivo.

Todavia, quando Authier-Revuz (1998) afirma que o interdiscurso corresponde ao 'isso fala', o sentido já-lá da heterogeneidade constitutiva, e ao como-diz-outro da heterogeneidade mostrada, o que observamos é que o que está sendo colocado em pauta é o visível, o mostrado, que, para a teoria da Análise do Discurso, corresponde ao dizível, ou seja, a relação do sujeito com as formações discursivas, com o interdiscurso.

Em Orlandi (2009) há a noção de heterogeneidade, que aparece em Authier-Revuz como sendo uma mistura de $(a+b)$, como algo irrecuperável e distinto. Dessa forma, a ilusão de o sujeito estar na origem do dizer permite a recuperação da homogeneidade, convivendo assim o visível e a unidade. Na Análise de Discurso, no entanto, é possível somente a combinação $a b$, onde não há possibilidade de recuperação da origem, visto que apenas efeitos estão lá, como já dissemos anteriormente.

O processo de indistinção dos dizeres sobre/de José de Alencar, no século XIX, determina o não-limite nessa relação com a alteridade, visto que o jogo com o outro, nesse espaço jornalístico, se desfaz pelo uso ou menção de um interlocutor. Dessa forma, o sujeito/ articulista que enuncia representa o 
dizer como sendo seu, porém, ocupa, ao mesmo tempo, a posição, em sua própria enunciação, de observador exterior à língua.

Nesses processos de indistinções do dizer pressupõem-se sujeitos e sentidos, embora ambos permaneçam incompletos. A noção de incompletude, discutida por Orlandi (1987), é a condição primária para que haja a existência da linguagem, do sujeito e do sentido, é possibilidade de os sentidos se deslizarem, tornarem-se outros. Trata-se do espaço "[...] onde o outro insurge como aquilo de que também poderia dizer-se, de que desejaria esconder, mas que permanece latente, como constante opção" (MORELLO, 1995, p.63).

A relação de alteridade configura-se como algo longe de ser unívoco e claro, algo que, ao contrário, é desorganizado e confuso. Assim, o modo de dizer do articulista/poeta está acoplado a um dizer outro, indistinto, que se dá na relação com a incompletude. O estranhamento com o "grande" Outro, da ordem do inconsciente, e o outro "pequenino", da enunciação, simboliza a eterna reivindicação do sujeito com o que lhe é próprio e original. A impressão mais concernente, a partir desse conjunto de observações, é a de que o sujeito origem (o da psicologia) precisa marcar o aprisionamento das palavras, dos sentidos como lhes sendo particular.

Outra resposta é a de que, instalados nos modos de evidência do sujeito, os sentidos produzem efeitos de retorno, de desdobramento, estendendose em repetições inesgotáveis, a partir de laços metaenunciativos, reflexivos, no fio discursivo. Nesse funcionamento, a alteridade passa a constituir um espaço heterogêneo e múltiplo de dizeres possíveis, em um espaço possível, a partir de uma memória da língua que se ressignifica na/pela história.

O efeito de retorno e de ressignificação dos sentidos, no espaço heterogêneo de dizeres indistintos e possíveis, torna necessário pensar a língua como espaço de memória. Assim sendo, a disposição dessa memória na língua admite um funcionamento de identificação, na própria correlação existente entre sujeito/língua. Todavia, existem valores discursivos que a todo o momento desafiam o trabalho com a língua em espaços discursivos institucionalizados, em nosso caso, o jornal. Isso se dá, pois, na consideração da existência de todo um imenso material simbólico, silenciado ao longo da história de colonização e, 
que, de alguma maneira, ainda significa, visto que esse funcionamento the é constitutivo, sendo não apenas uma partícula esparsa de significação no tempo, mas objeto simbólico próprio dessa rede de memória na língua.

Pensamos, dessa maneira, a memória a partir do campo da linguagem, na perspectiva do discurso, no qual se considera que a memória histórica está, enquanto gesto de leitura, condicionada aos enunciados, aos discursos, constituindo-os, e determinando suas formações discursivas.

Esse entendimento nos leva à seguinte proposição: a memória pelas vias do simbólico funciona determinada por certas formações discursivas, em escalas coletivas, bem como percorre esferas tidas como privadas e/ou pessoais, que, nesse caso, colocam em funcionamento alguns processos de silenciamento. Nessa direção, Payer considera que é necessário identificar

[...] o entrecruzamento destas duas esferas, coletiva e pessoal, [que] leva a desvendar o funcionamento de um meticuloso trabalhoda memória, na articulação, às vezes subterrânea e involuntária, do mnemônico com a palavra. A atenção a esta articulação resulta na impossibilidade de desconsiderarmos o sensível na produção do sujeito de linguagem, das práticas humanas e do próprio conhecimento. (PAYER, 2009, p.38)

Pensar o trabalho da memória discursiva enquanto aquilo que "fala antes, em outro lugar, independentemente" (PÊCHEUX, 1988) é compreender, desde os primórdios da teoria do discurso, "[...] o modo de existência histórica dos enunciados no seio das práticas sociais" (COURTINE, 1981 apud, PAYER, 2009), e considerar que há sempre um já-lá responsável por sustentar a possibilidade mesma de todo dizer. Nesse sentido, o discursivo estabelece uma relação de injunção com a memória, na medida em que os dizeres estão na base dos discursos outros, antecessores, que circulam na história das instituições.

Desse modo, é na própria estrutura enunciativa, na qual se encontram alguns indícios da memória no discurso ou, ainda, pelo seu funcionamento opaco, que afirmamos haver constantes marcas dos apagamentos de sentidos 
que estão inscritos nas práticas discursivas da língua. A memória dos dizeres, inscritas nos jornais que recortamos para leitura, por exemplo, lançam-se enquanto uma "supressão das citações entre um discurso primeiro e um discurso segundo que cita, onde se vê funcionar simultaneamente tanto a memória quanto o apagamento, a recitação de discursos em retomadas ritualísticas" (PAYER, 2009, p.40 41). Vejamos o enunciado ${ }^{10}$, publicado no jornal $A$ Opinião (1878):

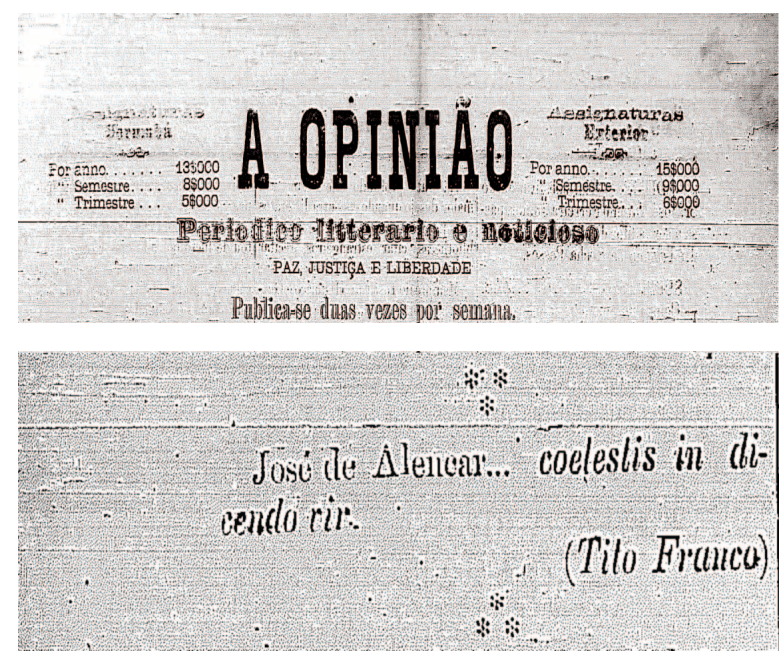

(Franco, ano I, p.04)

Especificamente nesse recorte ${ }^{11}$, temos uma proposição poética que se desenvolve a partir do sentido de um mote: a eloquência divina de José de Alencar em relação com a de Cícero ${ }^{12}$, que foi considerado uma das mentes mais brilhantes da época, sendo-lhe atribuída a responsabilidade por apresentar o pensamento grego aos romanos.

Nesse sentido, Franco, o articulista, brinca com uma possível supressão de um discurso primeiro, o do séc. I a.C., para, em um segundo momento discursivo, em tom de reminiscência, jogar com o espaço do 'outro', o interlocutor, evidenciando, desse modo, o efeito deste dizer, a partir de um funcionamento discursivo do século XIX, visto que a proposição, após as reticências, encontra-se em itálico. Configura-se, assim, o enunciado enquanto uma não-coincidência interlocutiva, dada por uma possibilidade própria da língua, por sua memória. 
Essa memória de uma língua outra, de um sujeito coletivo do século I a.C, apresenta-se como um arquivo da memória de outra língua na própria língua, a do XIX, trazendo, assim, para as cenas enunciativas a memória de uma alteridade constitutiva do sujeito brasileiro escritor. Nesse sentido, compreendemos o funcionamento da língua como "lugar de memória", e ainda mais, como lugar significativo de reconhecimento da memória.

Desse modo asseveramos: a dobra de mundos, sujeitos e sentidos produzindo ficção é um funcionamento próprio da língua, pois o sujeito não tem sempre um lócus de filiação. Ele é determinado sócio-historicamente e afetado pelo inconsciente. Não há dizeres preenchidos, conforme já propusemos, e pré-determinados. Afinal nenhuma língua pode ser pensada completamente sem a possibilidade de ficção e representação pela dobra.

De algum modo, coser considerações sobre a estreita tensão entre o jádito e o ainda por dizer, na história dos sentidos de um língua, oferece-nos abertura para pensar o intenso jogo entre o sedimentado e o a realizar-se, num espaço histórico em que, a partir de um ponto de articulação, o real, o simbólico, o sujeito e os sentidos escorregam por caminhos porosos, deslocando e repetindo, no corpo da linguagem, as possibilidades e/ou modos de subjetivação.

Alguns consideram o já-dito enquanto um fechamento dos sentidos, pois este, em certa medida, delimita, imobiliza. Entretanto, podemos pensar, com Orlandi (2009, p. 9), "[...] que aquilo que se diz, uma vez dito, vira coisa no mundo: ganha espessura, faz história”. Desse modo, apontar para o estabelecimento do não-estabelecido e questionar a consciência hegemônica (o sentimento) dessas distinções no homem de linguagem, fornece fôlego para a nossa concepção de trabalho, qual seja, a língua pensada por uma teoria materialista de linguagem. Também, a questão da memória se mostra sensível quando, sobretudo, "[...] ela opera sob a forma da evidência dos sentidos, aparecendo [...] nas suas falhas" (PAYER, 2009, p. 42).

Nesse sentido, o trabalho com a língua, enquanto lugar de memória,

[...] nos leva a compreender ainda que, em relação à língua, a memória histórico-discursiva que é constitutiva dos sujeitos nem sempre é representada como tal. Isso ocorre, entre outros fatores, 
em função dos saberes que a historiografia torna (ou não) disponível ao corpo social, pelas vias de uma escola que é também nacional, ela mesma parte do dispositivo da nacionalidade, conforme a racionalidade moderna. Mas também, por outro lado, esse funcionamento não deixa de operar na esfera do recalque, no sentido de que fatos vividos não foram simbolizados pelo/para o sujeito. (Idem, Ibidem, p.43)

Escavar, procurar os vastos indícios do funcionamento da memória na língua, face aos movimentos reflexivos dos sentidos, dos sujeitos no mundo, nos fará deparar com uma imensidão de valores materiais simbólicos que foram e que, de alguma maneira, continuam sendo soterrados por uma "racionalidade homogeneizante própria do Estado Moderno" (Idem, Ibidem, p.43).

Nessa direção, ao passo de compreendermos a memória na/da língua, não apenas enquanto jogos de palavras no tempo, mas enquanto trocas de olhares outros no mesmo e enquanto possibilidades de formulações indistintas e múltiplas, recobriremos parte do imenso material subterrâneo no qual, de certo modo, encontram-se armazenados os infinitos elementos de memória constitutiva da/na língua.

\section{Palavras (quase) finais}

[...] o simbólico faz a irrupção diretamente no corpo, as palavras tornam-se peças de órgãos, pedaços do corpo esfacelado que o "logófilo" vai desmontar e transformar para tentar reconstruir ao mesmo tempo a história de seu corpo e a da língua que nele se inscreve: essa loucura das palavras, que pode desembocar na escrita (Rabelais, Joyce, Artaud ou Beckett), na poesia (Mallarmé) ou na teoria linguística, persegue sem trégua o laço umbilical que liga o significante ao significado, para rompê-lo, reconstruí-lo ou transfigurá-lo.

(PÊCHEUX, 2010, p.45) 
Tendo como objeto de estudo a linguagem, as práticas dos dizeres do século XIX, partindo de uma teoria materialista, trabalhada por Orlandi (2005; 2009; 1996) e outros pesquisadores, no Brasil, e Pêcheux (1998) e Gadet \& Pêcheaux (2004), na França, pensamos um fecho para esta pesquisa, ainda que provisório. Antes, porém, se faz necessário dizer que um cisionismo é constitutivo da cientificidade da Análise de Discurso; prática de leitura grávida de uma teoria. De acordo com Orlandi (2009, p. 13) esse cisionismo se dará por dois motivos, o primeiro e o segundo, respectivamente:

[..., porque numa realidade social e histórica como a nossa, em que se é obrigado a reconhecer que sempre se ocupam determinadas posições (e não outras) no conflito constitutivo das relações sociais, não se pode fazê-lo neutramente, ou seja, sob a ilusão de que não se está tomando decisão nenhuma.

[...] porque as críticas que se voltam contra a $\mathrm{AD}$ constituem formas contínuas de anexação e de revisão de sua capacidade explicativa. Também quanto à AD, a "Razão Ocidental" [...] em concluir um pacto de coexistência pacífica [...] senão sob a condição de anexá-la às suas próprias ciências ou seus próprios mitos [...]. (ALTHUSSER, 1984, apud ORLANDI, 2009, p.13)

Nesse sentido, a Análise de Discurso tornou-se alvo de tentativas de anexação que tendem a silenciar a sua dimensão ideológica e a trabalhar o discurso enquanto uma espécie de adendo em relação ao linguístico, por exemplo. Assim, o trabalho teórico da Análise de Discurso constitui-se, pela sua completa desterritorialização, em face de três fundamentos: a ideologia, a crítica e a teoria. É nesse espaço triplo de fundamentos que pensamos para além, ou através da ficção, de uma língua o próprio investimento do funcionamento de um imaginário de língua literária, possível por uma memória dada a existir em poesia, metáfora. Assim, talvez, a palavra ficção definirá o modo como o inconsciente se diz na poesia. Afinal, é a própria ficção que, quando levada pelas palavras aos seus últimos limites simbólicos, conduzirá o imaginário imóvel a um 
processo simbólico, ou seja, no imaginário temos um sujeito relacionado com o "pequeno" outro, enquanto pela ficção o sujeito está em busca do "grande" Outro, do campo simbólico. O imaginário é a inconsciência do inconsciente às vezes buscada pelo sujeito para encobrir sua falta constitutiv,a e o real nesse espaço do próprio inconsciente é a possibilidade de infinitização da alteridade, aquilo que volta sempre no (ou não no) mesmo lugar.

Então, conforme proposto em análise, a experiência da alteridade significa-se reflexivamente no vazio do eco de nossas vozes e na opacidade de nossas palavras.

Nessa perspectiva, vemos nos jornais da segunda metade do século XIX o funcionamento discursivo do jogo simbólico, em que o discurso da língua se autorrepresenta. O simbólico joga diferentemente com sua materialidade para então se significar, justamente pela plasticidade própria à língua que abre a possibilidade de o significante, num gesto reflexivo, projetar-se sobre si mesmo, apontando para uma não-coincidência dos sentidos, dos sujeitos com o inconsciente e o interdiscurso.

Conhecendo as dobras da língua(gem), trabalhar efetivamente a memória da/na língua no sujeito nos levou a compreender questões de instâncias discursivas não somente ligadas à língua, mas, por conseguinte, também sobre a língua, inclusive aquilo que lhe parece subterrâneo. Nessa direção, consideramos que "[...] o sentido de uma palavra, de uma expressão, de uma proposição, etc., não existe 'em si mesmo', mas, ao contrário, pelo [...] processo sócio-histórico no qual as palavras, expressões e proposiçôes são produzidas (PÊCHEUX, 1998, p.190, grifo nosso), e ainda que há uma parte desses sentidos inacessíveis ao sujeito. Assim, consideramos que é pela relação da memória discursiva de uma língua (que por sua vez é constituída pela ideologia) com sua exterioridade que as possibilidades de retomada de sentidos preexistentes se torna possível no espaço de constituição dos jornais do XIX, sobretudo, a partir da relação necessária da linguagem com o seu equívoco.

Nessa direção, faz-se necessário afirmar que, quando alinhavamos um percurso de leitura sobre o objeto em análise, algo do que propusemos inicialmente não ganhou espaço na discussão, isso porque "[...] são as noções e con- 
ceitos que significam na relação com os materiais tomados para análise, tomando distintas configurações em cada análise” (LAGAZZI, 2009 p.68). Assim sendo, questões como o ritual com falhas, pensado na cadeia significante e seus efeitos de sentidos na linguagem, deverão constituir espaço para possíveis (re)tomadas de leituras, haja vista considerarmos que o ritual discursivo se estilhaça no lapso, e este não necessariamente coincide com a ideologia, afinal a ideologia não deve ser pensada necessariamente sem referência ao registro inconsciente, o que nos possibilita, em um segundo momento de leitura, questionar o modo como se dá a circularidade do projeto literário, em Mato Grosso, no espaço do jornal, e, assim, aprioristicamente, apontar essa inscrição literária no jornal enquanto uma falha discursiva, resultante de uma subjetivação que reflete em uma construção identitária, constituída por uma heterogeneidade discursiva, imbricada com a história, e atravessada pela memória da língua.

Dessa maneira, é pela possibilidade intrínseca à língua - a possibilidade da reflexividade - que sustentamos cada (re)tomada de leitura em análise, (re)tomadas enquanto propostas cuja finalidade é a de tocar o interior da linguagem, como um modo de enunciação dobrado entre os coenunciadores, e de trabalhar o espaço de infinitas dissensões, a partir da representação do sujeito articulista/literato no discurso tal como "[...] ele se realiza através de uma conjunção de marcas formais e discursivas - que implicadas na organização do dizer, the confere uma unidade face ao que é fundamentalmente disperso: o discurso é uma dispersão de textos" (MORELLO, 1995, p.54).

Essa dispersão a autora afirma encontrar-se relacionada à emergência de uma estrutura meta no sujeito da contemporaneidade. Afinal, toda menção à língua é própria da atividade da linguagem, e, de algum modo, podemos propor que o gesto de fazer menção está acoplado a um dizer outro, indistinto, que se dá na relação com a incompletude, incompletude que reivindica ao sujeito o que lhe é próprio e original no movimento mesmo de reiteração dos sentidos, da hiância de marcar um sujeito nacional em seu tempo/espaço.

Nesse sentido, a insurgência do outro/Outro, a se misturar no discurso do sujeito enunciador, joga sempre numa bivalência de presença/ausência sem fronteiras, e também estabelece um espaço de recorrência de processos de sig- 
nificação infinitamente mais complexos, pois são

[...] as marcas do dizer vêm configurar gestos discursivos onde, por um incessante retorno do sujeito (e dos sentidos) ao universo dos dizeres estabilizados (PÊCHEUX, 1983) e pela iminência de um outro sempre possível, desestabilizando esse movimento, jogam representações, equivalentes ou não, desse real. (MORELLO, 1995, p.72)

Por ora, a partir dessa proposição de leitura do sentido sobre o sentido, do sujeito sobre o sentido, etc., ainda é possível considerar que, "[...] por entre as imagens cerradas nos seus últimos limites [...], aconteceu, apesar da loucura das palavras que pode desembocar na loucura da escrita (PÊCHEUX, 2010, 45), o passar da flecha do discurso" (Bosi, 2000, p.42).

\section{Referências}

ALMEIDA, Eliana de. Poesia: uma história das ideias linguísticas. In. Anais do $1^{\circ}$ CIELLI, Maringá-PR, 9, 10 e 11 de junho de 2010.

ALTHUSSER, Louis. Aparelhos ideológicos de Estado. 2. ed. Trad. de Valter José Evangelista e Maria Laura Viveiros de Castro. Rio de Janeiro: Graal, 1984

AUTHIER-REVUZ. Falta do dizer, dizer da falta: as palavras do silêncio. IN: ORLANDI, E. P. et al. Gestos de leitura: da história do discurso. Campinas: Editora da Unicamp, 2010, pp. 253-277.

AUTHIER-REVUZ. Dialogismo e divulgação científica. In: Rua: revista do Núcleo de Desenvolvimento da Criatividade. Número 5, março de 1999. Campinas, SP. AUTHIER-REVUZ. As não-coincidências do dizer. In: Palavras incertas: as nãocoincidências do dizer. Campinas, São Paulo: Ed. UNICAMP, 1998, p. 13-28. AUTHIER-REVUZ. Heterogeneidade(s) enunciativa(s). Trad. de Celene M. Cruz e João Wanderley Geraldi. In: Cadernos de estudos linguísticos 19. O Discurso e suas análises. ORLANDI, E. P. e GERALDI, J. W. (Orgs.) Campinas: UNICAMP, 1990, p. 25-42.

BLANCHOT, M. O espaço literário. Rio de Janeiro: Rocco, 1987. 
BOSI, Alfredo. O ser e o tempo da poesia. Companhia das Letras, 2000.

COURTINE, J. Le discours communiste adressée aux chrétiens. Langages, Paris, número 62, 1981.

DIAS.G. Notas Literárias. Jornal A Opinião, Cuiabá. Ano I, 1878. Página Literatura e Sociedade, Caderno 3.

FRANÇA, Carlos. Notas Literárias. Jornal A Opinião, Cuiabá. Ano I, 1878. Página Literatura e Sociedade, Caderno 3.

GADET, F.; PÊCHEUX, M. [1981] A língua inatingível. Campinas: Pontes, 2004.

LAGAZZI, S. Recorte significante na memória. In: INDURSKY, Freeda et al. O discurso na contemporaneidade: materialidades e fronteiras, São Carlos: Claraluz, 2009, p. 67-78

LEITE, N. V. A., Psicanálise e literatura. In: Revista de linguagem, cultura e discurso. N. 7, Campinas: SP, 2007.

MARIANI, B. Pátria independente: outras palavras? In: Organon 21, Revista do Instituto de Letras da Universidade Federal do Rio Grande do Sul, s/d.

MARIANI, B. Língua nacional e pontos de subjetivação. In: Revista Estudos Linguísticos, N. 37 (3): 25 - 31, São Paulo, 2008.

MARIANI, B. Colonização linguística: língua, política e religião no brasil (séculos XVI a XVIII) e nos Estados Unidos da América (século xviii). São Paulo: Pontes, 2007.

MARIANI, B.. Subjetividade e imaginário linguístico. In: Lingua(gem) em discurso - Subjetividade. V.3, número especial, Tubarão, SC, Rev. da UNISUL, 2004. MORELLO, Rosângela. Os meandros da alteridade: marcas de dizer e indistinção de vozes no discurso. Campinas/SP; UNICAMP, 1995.

OlIVEIRA, Mariano. Notas Literárias. Jornal A Opinião, Cuiabá. Ano I, 1878. Página Literatura e Sociedade, Caderno 3.

ORLANDI, E. P. A Linguagem e seu funcionamento: as formas do discurso. Ed, 5‥ Campinas, SP: Pontes, 2009.

ORLANDI, E. P. Análise de Discurso: princípios e procedimentos. 7a ed. Campinas, SP: Pontes, 2007.

ORLANDI, E. P. Análise do Discurso: princípios Éprocedimentos. Ed. $6^{\circ}$. São Paulo: Pontes, 2005. 
ORLANDI, E. P. Lingua e conhecimento linguístico. São Paulo, SP: Cortez, 2002. ORLANDI, E. P. (org.). História das idéias linguísticas. Campinas: Ed. Pontes; Cáceres, Unemat, 2001.

ORLANDI, E. P. O próprio da Análise de Discurso. Escritos. (Unicamp), São Paulo, n. 3, 1999.

ORLANDI, E. P. Interpretação. Autoria, leitura e efeitos do trabalho simbólico. Petrópolis: Ed. Vozes, 1996.

ORLANDI, E. P. Não o outro, mas o diferente. In: Terra à vista - discurso do confronto: velho e novo mundo. Cortez; São Paulo: Ed. Campinas, 1990, p. 3844 .

ORLANDI, E. P. Segmentar ou recortar? Série Estudos, n. 10. Uberaba, MG, 1987. PAYER, M. O imigrante, sujeito moderno. Processos de objetivação do sujeito e da lingua na modernidade. In: Zoppi-Fontana (org.). Línguas for Sport. Campinas, 2009.

PAYER, O. O trabalho com a lingua como lugar de memória. Synergies Brésil $\mathrm{n}^{\circ} 7-2009$ p. 37-46.

PAYER, O. Memória da língua; imigração e nacionalidade. São Paulo: Ed. Escuta, 2006.

PEÇANHA, J. Notas Literárias. Jornal A Opinião, Cuiabá. Ano I, 1878. Página Literatura e Sociedade, Caderno 3.

PÊCHEUX, M. Sobre os contextos epistemológicos da análise do discurso. In: Revista Escritos, no ${ }^{-4}$. Campinas, SP: LABEURB, 2010.

PÊCHEUX, M. Semântica e discurso: Uma crítica à afirmação do óbvio.Trad. Eni P. Orlandi. Campinas: Editora da UNICAMP, 1998. (Coleção Repertórios).

PÊCHEUX, M. A Análise do Discurso: três épocas. Tradução de Jonas de A. Romualdo. In: GADET, F. \& HAK, T. (orgs.) Por uma análise automática do discurso: uma introdução à obra de Michel Pêcheux. Campinas, Editora da Unicamp, 1997. [1983]

PÊCHEUX, M. O discurso: estrutura ou acontecimento. Campinas: Pontes, 1990. PÊCHEUX, M. Semântica e discurso: uma crítica à afirmação do óbvio. Tradução Eni Orlandi. Campinas, SP: Editora da UNICAMP, 1988.

TAUNAY, Escragnolle. Notas Literárias. Jornal A Opinião, Cuiabá. Ano I, 1878. 
Página Literatura e Sociedade, Caderno 3.

TAVARES. J. Uma homenagem ao poeta Alencar. Jornal O Povo, Cuiabá. Ano I, 1879. Notas breves. Caderno 2.

${ }^{1}$ Mestrando em Ciências da Linguagem pela Universidade do Vale do Sapucaí.

${ }^{2}$ Literatura: José de Alencar - O Brasil gigantesco berço de talentosos portentosos: De Gonçalves Dias, o mavioso poeta, cuja alma eleva-se as supremas regiões à vista das verdejantes palmeiras de sua terra natal, à hora em que o sabiá, ao descambar do sol, desprende melancolicamente sua última endeixa; [...].(TAVARES J. ano I, 1879).।

${ }^{3}$ Vinde, casta e gentil Cecy, melancólica Izabel, graciosa Guida! Vinde, meiga e dôce Iracema, caprichosa Diva, e vós altiva Senhora! Vinde todas - formosas filhas do genio de Alencar - entretecer uma capella de brancas saudades para aquelle que vos deu vida ideal, cheia de luz e de immarcessiveis encantos!

${ }^{4}$ Compreendemos hiância enquanto um intervalo de vazio significante onde "habita", na gnoseologia lacaniana, a fantasia, que é a relação do sujeito com o seu objeto.

${ }^{5}$ A terceira das não-coincidências do dizer - a das palavras em relação às coisas - diz respeito a formas que deslocam hesitações, buscas e dúvidas sobre o tempo a ser empregado, possibilitando o rompimento da relação biunívoca ilusória entre as palavras e as coisas, o que traduz a impossibilidade de capturar o objeto representado apenas pela letra.

${ }^{6}$ Entre as joias preciosas do rico thesouro com que José de Alencar, ennobrecendo a patria, immortalisou seu nome, se admiro sempre a grandeza de seu talento, a seiva inesgotavel de suas inspirações, e o vasto cabedal de conhecimentos que tanto realçavam suas obras, a que mais me encantou foi o primoroso mimo de sua imaginação de poeta, intitulado Sonhos de Ouro. Não terá porventura o meritointrinseco de muitas de suas outras produçções, não revelará como nestas o estudo e a meditação, mas nenhuma deleita mais o espirito, porque nenhuma seguramente a excede na belleza da forma, na naturalidade do entrecho, e, mais que tudo, na pureza e elevação do sentimento. Nos Sonhos de Ouro é protagonista o coração em toda gala e esplendor de seus primeiros impulsos e percorrendo embevecido a escala esperançosa das emoções electricas do amor. Os Sonhos de Ouro, ainda uma vez o digo, são o transumpto perfeito da alma de José de Alencar. (J.P de Azevedo Peçanha).

${ }^{7}$ Era uma lâmpada fragil - à força de tanta luz - estalou. Carlos França ${ }^{8}$ Passaram-lhe ahi dolorosas pela imaginação estas verdades: "Vão-se todos os nossos homens de talento”. Agora este, que escreveu tantos etãobellos livros! Era o autor do 
GUARANY. Esse GUARANY está hoje traduzido na Europa e deu ensejo ao apparecimento de um grande maestro nacional. Era uma gloria do paizesse imaginoso escriptor, e eu gostava delle porque era meu collega e além disto - porque era meu patricio. Sintome abatido e triste..."

${ }^{9}$ Para recebel-o não bastava o tumulo - o abysmo mais profundo - na phrase de Hugo. E por isso que ao ver rachar-se hoje o terreno em fogo da sua provincia parece-me que esta se abre em uma sepultura enorme para receber aquelle grande morto. O Ceará teve espaço para enterrar todo um povo; é pequeno, no entanto, para tumulo d'aquelle homem. Mariano de Oliveira.

${ }^{10}$ José de Alencar... Coelestis in dicendo vir. (TitoFranco)

${ }^{11}$ Coelestis - e. $1^{\text {o }}$ Du ciel, célest; $2^{\circ}$ Divin; $3^{\circ}$ Au fig. Divin, semblableauxdieux. Coelestis in dicendo vir - Quint. Homme d'une éloquencedivine. Caelestissimum os Ciceronis. Vell. L'eloquenceincomparable de Cicéron. Caelestissima opera. Vell. Ouvragesmerveilleux. I I coelestior. Sem. (DictionnaireLatin-Français, Paris, 1846)

${ }^{12}$ Pensador romano, filósofo, orador, escritor, etc., do século I a.C.

Data de submissão: 27/12/2011

Data de aprovação: 14/08/2012 